\title{
How Financial Education affects Mathematics performance? Evidence from Spain in the context of the Program School 2.0
}

\author{
C. Vilaplana-Prieto* \\ * University of Murcia (Spain)
}

\begin{abstract}
In this paper we evaluate the effect of participation in the Program School 2.0 on both Financial Education and Mathematics performance using data from PISA 2012. The School 2.0 Program was implemented in 2009 in some Spanish Autonomous Communities. This program promoted the use of computers, both in school and at home, among elementary and high school students. We detect that a greater benefit is obtained when the contents of Financial Education are taught in conjunction with the contents of the subject of Mathematics, although the mean effect of Financial Education over Mathematics is more intense in Communities that have not participated in the Program School 2.0. This result may be related to the fact that only a moderate use of computer for personal use increases Mathematics and Financial Education performance. Nevertheless, given the recent implementation of the Program School 2.0, we should expect some "learning effects" that should be confirmed with future data.
\end{abstract}

Keywords: Program evaluation; PISA; Financial Education; Mathematics

\section{Introduction}

The recent economic and financial crisis has demonstrated that economic recovery requires the participation of all economic stakeholders (Lester and Williams, 2010). Financial Education enables the individual to acquire a series of very useful skills for adulthood and this should be a component of student learning. Studies have indicated that people who have received Financial Education show a greater tendency to manage their savings before retirement (Cole et al., 2010), participate more in the stock markets (Van Rooij et al., 2011), and take greater care when choosing mortgages or loans with lower interests and fees (Lusardi and Tufano, 2009).

As indicated by Lusardi and Mitchell (2009), the incorporation of Financial Education into the academic curriculum has a positive impact on young people and facilitates the development of skills in the areas of savings, loans, investments, critical thinking and problem solving.

This article analyses the relationship between performances in Mathematics and Financial Education, subject to their participation in School Program 2.0. First, some studies (Suiter and McCorkle, 2008) have found that the melding of Mathematics and Financial Education favours the development of responsible financial behaviours. Second, the majority of problems that students need to resolve on the PISA-Financial questionnaire require the completion of numerical calculations. In addition to linking Mathematics and Financial Education skills, this paper aims at introducing a third analytical element: the influence of ICT (Information and Communication Technologies) in schools in regards to School Program 2.0.

\section{Material and Methods}

\section{Program School 2.0}

In July 2009, the Spanish Education Sector Conference adopted an investment of $€ 98,182,419$ for the implementation of the Program School 2.0 (Resolution of 3 August, 
2009, of the Technical Secretariat General, for which it published the Agreement of the Council of Ministers of 31 July, 2009)

The allocation of these funds was to co-finance $50 \%$ of the following activities, within the Autonomous Communities: (1) The transformation of all 5th and 6th Primary Education and all 1st and 2nd Compulsory Secondary Education classrooms into digital classrooms at public schools; (2) The provision of computers for the personal use, (3) The development of digital content that may be used by teachers. However, the Autonomous Communities' participation in School Program 2.0 was not homogeneous and three levels of participation were discernible:

(i) Total Participant Communities (TP): Andalusia, Aragon, Cantabria, CastileLeon, Castilla-La Mancha, Catalonia, Extremadura, Galicia, Navarra, Basque Country, La Rioja, Ceuta and Melilla

(ii) Partial Participant Communities (PP): Asturias, Balearic and Canary Islands. These one will not be considered in the following analysis.

(iii) Non-participat Communities (NP): Madrid, Murcia and the Valencian Community.

\section{Econometric model}

We consider two latent variables $\mathrm{FE}_{\mathrm{i}}^{*}$ and $\mathrm{MAT}_{\mathrm{i}}^{*}$ that denote "knowledge in Financial Education" and "knowledge in Mathematics", respectively. Both variables are influenced by observable characteristics (family group, resources available at home and at the school) and unobservable characteristics (innate aptitudes of students, their level of motivation). Additionally, the relationship between them can flow in both directions. On the one hand, Financial Education can provide a more applied perspective for certain mathematical concepts, so it can be useful to reduce the degree of abstraction that is so often argued as a difficulty by students when dealing with exact sciences. Moreover, students with a greater ability for numerical reasoning may find it easy and attractive to choose the field of Financial Education. In general, the score obtained in both areas may be expressed using the following system:

$$
\begin{aligned}
& F E_{i}^{*}=X_{1 i}^{\prime} \beta_{1}+\varepsilon_{1 i} \\
& M A T_{i}^{*}=\alpha E F_{i}^{*}+X_{2 i}^{\prime} \beta_{2}+\varepsilon_{2 i}
\end{aligned}
$$

where $X_{1 \mathrm{i}}^{\prime}$ and $X_{2 \mathrm{i}}^{\prime}$ are vectors of observable characteristics, $\beta_{1}$ and $\beta_{2}$ are vectors of parameters, $\varepsilon_{1 \mathrm{i}}$ and $\varepsilon_{2 \mathrm{i}}$ are both error terms, which we assumed follow a bivariate normal distribution with zero mean, unit variance and correlation coefficient: $\rho$ :

$$
\left(\begin{array}{l}
\varepsilon_{1 i} \\
\varepsilon_{2 i}
\end{array}\right) \sim N\left(\left(\begin{array}{l}
0 \\
0
\end{array}\right),\left(\begin{array}{ll}
1 & \rho \\
\rho & 1
\end{array}\right)\right)
$$

and such that $\mathrm{E}\left[\mathrm{X}_{1 \mathrm{i}}^{\prime}, \varepsilon_{1 \mathrm{i}}\right]=0$ and $\mathrm{E}\left[\mathrm{X}_{2 \mathrm{i}}^{\prime}, \varepsilon_{2 \mathrm{i}}\right]=0$. Thus, if $\rho$ is equal to zero, $\mathrm{FE}_{\mathrm{i}}^{*}$ it is not endogenously determined and both equations may be solved separately.

The following explanatory variables were introduced in both equations: characteristics of students and family (gender, nationality, repetition of grade level, availability of a computer at home, educational level of parents), and characteristics of the school (average size of class, ratio of schoolgirls at the school, size of residing municipality). In the equation for MAT, we considered the following explanatory variables: if there is a school-policy on the use of computers in the classroom and on the quality assessment of Mathematics, the percentage of teachers with ISCED5A qualifications, if the student has a computer in the classroom and the frequency of ICT use to do homework. 
In the equation for FE, explanatory variables introduced were the following: if the contents of Financial Education are compulsory, if it is delivered within a specific subject (Mathematics, Economics, Social Sciences and Humanities), the length of time Finance Education has been delivered, if teaching staff of Financial Education belong to the school's faculty and if the teachers have received specific training.

Regarding student environment, two instrumental variables were introduced taking as a reference evidence from the literature on Financial Education (Pinto et al., 2005; Williams, 2010): (i) a binary variable that takes value 1 if the student indicates talking to his/her parents almost every day or 1-2 times a week about financial issues (savings, household spending, banks, etc.) and (ii) a binary variable that takes value 1 if the student indicates earning money from working (tutoring, babysitting) or helping out in a family business.

However, we did not observe the level of knowledge in Mathematics and in Financial Education $\left(\mathrm{FE}_{\mathrm{i}}^{*}\right.$ or $\mathrm{MAT}_{\mathrm{i}}^{*}$ ), rather the results of PISA (FE $\mathrm{F}_{\mathrm{i}}$ and $\mathrm{MAT}_{\mathrm{i}}$ ). PISA (2012) scores are based on calculations on a metric scale, with a 500 point average for all OECD countries and a standard deviation of 100 points. For a better understanding, they are usually divided into proficiency levels. This classification, recommended by PISA Technical Report is useful because it allow us to communicate about the proficiency of students in terms other than numbers.

The variable $\mathrm{FE}_{\mathrm{i}}$ is an ordered variable that classifies the PISA-Financial results into 5 levels: (1) "lowest performers": less than 400.33 points, (2) "low performers": between 400.33 and 475.10 points, (3) "moderate performers": between 475.10 and 549.86 point, (4) "strong performers": between 549.86 and 624.63 points and (5) "top performers": over 624.63 points.

The variable $\mathrm{MAT}_{\mathrm{i}}$ is another ordered variable that classifies the PISA-Mathematics results into 6 Levels: (1) "lowest performers": less than 357.7 points, (2) "low performers": between 357.5 and 420.1 points, (3) "low moderate performers": between 420.1 and 482.4 points, (4) "high moderate performers": between 482.4 and 544.7 points, (5) "strong performers" between 544.7 and 607 points and (6) "top performers": over 607 points. Observed variables are linked to the latent variables according to the following expressions:

$$
\begin{gathered}
F E_{i}=\left\{\begin{array}{l}
1 \text { if } F E_{i}^{*}<\omega_{1} \\
2 \text { if } \omega_{1}<F E_{i}^{*}<\omega_{2} \\
3 \text { if } \omega_{2}<F E_{i}^{*}<\omega_{3} \\
4 \text { if } \omega_{3}<F E_{i}^{*}<\omega_{4} \\
5 \text { if } \omega_{4}<F E_{i}^{*}
\end{array}\right. \\
M A T_{i}=\left\{\begin{array}{l}
1 \text { if } M A T_{i}^{*}<\tau_{1} \\
2 \text { if } \tau_{1}<M A T_{i}^{*}<\tau_{2} \\
3 \text { if } \tau_{2}<M A T_{i}^{*}<\tau_{3} \\
4 \text { if } \tau_{3}<M A T_{i}^{*}<\tau_{4} \\
5 \text { if } \tau_{4}<M A T_{i}^{*}<\tau_{5} \\
6 \text { if } \tau_{5}<M A T_{i}^{*}
\end{array}\right.
\end{gathered}
$$

where $\omega_{1}<\omega_{2}<\omega_{3}<\omega_{4}$ and $\tau_{1}<\tau_{2}<\tau_{3}<\tau_{4}<\tau_{5}$ are the cut-off points.

We proceeded to calculate two bivariate probit models. In the first one, the effect of EF on MAT is considered as a constant, and therefore, a standard ordered bivariate probit model was calculated. The second alternative is a bivariate probit with mixed effects assuming that the parameter $\alpha$ follows a normal distribution with mean $\mu_{\alpha}$ and standard deviation $\sigma_{\alpha}$. The denomination "mixed effects" makes reference to the existence of 
heterogeneity regarding the impact of FE over MAT across students. Using a statistical distribution allow us to distinguish between those who are able to transform the skills gained in FE into better results in MAT, and also, those students with higher difficulty in cross-curriculum learning in MAT from skills learned in FE. With regard to computational aspects, the calculation for the standard model was done using the command proposed by Sajaia (2008), while for the model with mixed effects we have adapted the routine proposed by Buscha and Conte (2010).

\section{Data}

PISA is a cross-sectional study, conducted every three years that commenced in 2000 for 15 year old students, with the purpose of evaluating their performance in the areas of mathematics, reading and science, as well as cross-curriculum problem solving skills. In addition to the general module and the CBA module (computer based assessment), a third type of test was conducted to measure financial literacy.

Regarding the specific module concerning Financial Education, the sample for Spain contains 1,108 observations, even if we restrict the sample to public schools this is reduced to 765 observations. Regarding participation in School Program 2.0, there are 167 observations for non-participating communities (NP), 532 for totally participating Communities (TP) and 66 for partially participating Communities (PP). In this paper we will only focus on TP and NP Communities.

\section{Results and Discussion}

Table 1 shows the results for the models of TP Communities with and without mixed effects, and Table 2 offers the same results for NP Communities. This existence of substantial heterogeneity in the effect of Financial Education on the results in Mathematics among the students is confirmed by the significance of the parameters $(\mu$ and $\sigma$ ) for TP and NP Communities.

In both types of Communities, a moderate use of computer/tablet, whether for homework or for class lessons, is associated with a better performance in Mathematics and Financial Education. Nevertheless, this positive effect is not observe for the case of almost daily or everyday use. This result could be indicative that the adaptation process to new methodologies may require a revision. For the model with mixed effects for TP Communities, schools that have a policy on the use of computers in the classroom and for quality assessment in Mathematics tend to score higher for this subject.

Regarding to the placement of Financial Education in the teaching project, a positive effect is observed when there is an obligation to teach this subject and it has been delivered for more than two years at the school. The latter result may be related to the existence of learning outcomes within the teaching plans, since with an increased number of years of "running", teachers know better how to reach students.

Talking with parents about issues related to Financial Education or having work are significant positive variables, with the first variable having great influence on the score for Financial Education.

The fact that teaching faculty corresponds to the school teachers instead of professionals from public, private or NGOs is not significant for TP Communities, but it is (positively) for NP Communities. The percentage of teachers who have received 
specific training in Financial Education during the past year is not significant for TP Communities, however, it is for NP Communities.

Table 1. Estimation of Bivariate Ordered Probit Model for Mathematics and Financial Education Scores. Communities with Total Participation

\begin{tabular}{|c|c|c|c|c|c|c|}
\hline \multirow[b]{2}{*}{ Mathematics } & \multicolumn{3}{|c|}{ Without Mixed Effects } & \multicolumn{3}{|c|}{ With Mixed Effects } \\
\hline & Coef & Std.D & & Coef & Std.D & \\
\hline Financial Education Score & 1.215 & 0.069 & $* * *$ & & & \\
\hline Student (boy) & 0.457 & 0.103 & $* * *$ & 0.433 & 0.193 & $* * *$ \\
\hline Immigrant & -0.149 & 0.077 & $* *$ & -0.339 & 0.090 & $* * *$ \\
\hline Non-repeating & 0.175 & 0.041 & $* *$ & 0.334 & 0.045 & $* * *$ \\
\hline Use of Computers Policy & 0.224 & 0.100 & $* *$ & 0.180 & 0.032 & $* * *$ \\
\hline Mathematics Quality Policy & 0.011 & 0.163 & & 0.050 & 0.028 & $*$ \\
\hline Average Class Size & 0.005 & 0.007 & & -0.006 & 0.008 & \\
\hline Ratio of Schoolgirls & -0.928 & 0.360 & ** & -0.599 & 0.413 & \\
\hline Ratio of ISCED5A Teachers & 0.142 & 0.110 & & 0.181 & 0.143 & $* *$ \\
\hline Computer/tablet at home & 0.349 & 0.117 & $* * *$ & 0.431 & 0.218 & $* *$ \\
\hline Computer/tablet at school & -0.136 & 0.010 & $* * *$ & -0.146 & 0.035 & $* * *$ \\
\hline ICT for homework & & & & & & $* * *$ \\
\hline $1-2$ times/week & 0.230 & 0.113 & ** & 0.141 & 0.148 & \\
\hline Almost every day & -0.068 & 0.011 & $* * *$ & -0.245 & 0.105 & $* *$ \\
\hline Everyday & -0.440 & 0.241 & $* *$ & -0.695 & 0.288 & $* * *$ \\
\hline \multicolumn{7}{|l|}{ Financial Education } \\
\hline Non-repeating & 1.198 & 0.121 & $* * *$ & 1.250 & 0.236 & $* * *$ \\
\hline Student (boy) & 0.363 & 0.091 & $* * *$ & 0.315 & 0.102 & $* * *$ \\
\hline Immigrant & -0.305 & 0.162 & $*$ & -0.238 & 0.108 & $*$ \\
\hline Student talks to parents & 0.092 & 0.011 & $* * *$ & 0.172 & 0.011 & $* * *$ \\
\hline Student works & 0.041 & 0.071 & $* *$ & 0.102 & 0.026 & $* * *$ \\
\hline Computer/tablet at home & 0.454 & 0.205 & $* * *$ & 0.239 & 0.146 & $* * *$ \\
\hline Subject, less than 2 years ago & 0.304 & 0.154 & $* *$ & 0.572 & 0.192 & $* *$ \\
\hline Subject, more that 2 years ago & 0.407 & 0.202 & $* *$ & 0.635 & 0.188 & $* *$ \\
\hline Compulsory subject & 0.276 & 0.155 & $*$ & 0.664 & 0.207 & $*$ \\
\hline \multicolumn{7}{|l|}{ Explanation } \\
\hline Cross-curricular subject & -0.342 & 0.126 & $* * *$ & -0.403 & 0.177 & $* * *$ \\
\hline Within Economics Subject & -0.331 & 0.013 & $* *$ & -0.420 & 0.137 & $* *$ \\
\hline Within Mathematics Subject & 0.270 & 0.065 & $* * *$ & 0.221 & 0.103 & $* * *$ \\
\hline Within Science or Humanities Subjects & -0.128 & 0.050 & $* *$ & -0.093 & 0.177 & $* *$ \\
\hline Teacher Training Courses & 0.042 & 0.139 & & 0.086 & 0.135 & \\
\hline Teacher: Teacher from School & 0.175 & 0.147 & & 0.260 & 0.156 & \\
\hline Average Class Size & -0.016 & 0.006 & ** & -0.023 & 0.175 & ** \\
\hline Ratio of Schoolgirls & -0.066 & 0.281 & & -0.017 & 0.007 & \\
\hline \multicolumn{7}{|l|}{ Interaction: Computer/tablet at school and } \\
\hline Financial Education within Mathematics & -0.485 & 0.056 & $* * *$ & -0.602 & 0.289 & $* * *$ \\
\hline \multicolumn{7}{|l|}{ Interaction: ICT for homework and in Financial } \\
\hline $1-2$ times/week & 0.207 & 0.062 & $* *$ & 0.326 & 0.173 & $* *$ \\
\hline Almost every day & -0.192 & 0.082 & $* *$ & -0.047 & 0.200 & $* *$ \\
\hline Everyday & -0.804 & 0.323 & $* *$ & -0.147 & 0.278 & $* *$ \\
\hline Constant & -0.736 & 0.245 & $* * *$ & -0.935 & 0.445 & $* * *$ \\
\hline$\mu($ mixed effect $)$ & & & & 1.222 & 0.254 & $* * *$ \\
\hline$\sigma($ mixed effect $)$ & & & & 0.653 & 0.287 & $* * *$ \\
\hline$\rho$ & 0.627 & 0.149 & $* * *$ & 0.351 & 0.178 & $* * *$ \\
\hline Log likelihood & & $-1,174.959$ & & & $-1,147.912$ & \\
\hline $\mathrm{N}$ & & 532 & & & 532 & \\
\hline
\end{tabular}

All cut-off points are significant at 5\%. In both equations, the size of the residing municipality and the highest educational level of the father/mother have been included as an explanatory variable. Omitted variables: schoolgirls, repeating students, national, use computer for homework 1-2 times/month or less frequently, non-compulsory Financial Education, Financial Education subject not available. (***: Significant at $1 \% ; * *$ : significant at $5 \%$; : significant at $10 \%$ ).

Table 2. Estimation of Bivariate Ordered Probit Model for Mathematics and Financial Education Scores. Nonparticipating Communities

\begin{tabular}{lccccc}
\hline & \multicolumn{2}{c}{ Without Mixed Effects } & \multicolumn{2}{c}{ With Mixed Effects } \\
Mathematics & Coef & Std.D & & Coef & Std.D \\
\hline Financial Education Score & 1.291 & 0.142 & $* * *$ & & \\
Student (boy) & 0.688 & 0.199 & $* * *$ & 0.624 & 0.201 \\
Immigrant & -0.616 & 0.278 & $* *$ & -1.844 & 0.419 \\
Non-repeating & 0.826 & 0.338 & $* *$ & 2.051 & 0.548 \\
Use of Computers Policy & 0.332 & 0.203 & & 0.490 & 0.858 \\
Mathematics Quality Policy & 0.547 & 0.371 & & 1.670 & 2.336 \\
Average Class Size & -0.040 & 0.025 & & -0.142 & 0.199 \\
Ratio of Schoolgirls at class & -1.257 & 0.568 & & 1.060 & 2.313
\end{tabular}




\begin{tabular}{|c|c|c|c|c|c|c|}
\hline Computer/tablet at home & 0.592 & 0.256 & $* *$ & 0.845 & 0.316 & $* *$ \\
\hline Computer/tablet at school & -0.064 & 0.021 & $* * *$ & -0.226 & 0.112 & $* *$ \\
\hline \multicolumn{7}{|l|}{ ICT for homework } \\
\hline 1-2 times/week & 0.029 & 0.009 & $* * *$ & 0.021 & 0.006 & $* * *$ \\
\hline Almost every day & -0.049 & 0.024 & $* *$ & -0.216 & 1.482 & $* *$ \\
\hline Everyday & -0.102 & 0.050 & $* *$ & -0.614 & 0.201 & $* * *$ \\
\hline \multicolumn{7}{|l|}{ Financial Education } \\
\hline Non-repeating & 1.180 & 0.210 & $* * *$ & 1.240 & 0.189 & $* * *$ \\
\hline Student (boy) & 0.350 & 0.128 & $* *$ & 0.310 & 0.098 & $* * *$ \\
\hline Immigrant & -0.503 & 0.272 & $*$ & -0.391 & 0.115 & $*$ \\
\hline Student talks to parents & 0.228 & 0.100 & $* *$ & 0.344 & 0.165 & $* *$ \\
\hline Student works & 0.257 & 0.130 & $* *$ & 0.195 & 0.068 & $* * *$ \\
\hline Computer/tablet at home & 0.631 & 0.349 & $* *$ & 0.241 & 0.108 & $* *$ \\
\hline Subject, less than 2 years ago & 0.121 & 0.016 & $* * *$ & 0.798 & 0.378 & $* *$ \\
\hline Subject, more than 2 years ago & 0.728 & 0.321 & $* *$ & 0.941 & 0.450 & $* *$ \\
\hline Compulsory subject & - & - & & - & - & \\
\hline \multicolumn{7}{|l|}{ Explanation } \\
\hline Cross-curricular subject & -0.607 & 0.134 & $* * *$ & -0.214 & 0.064 & $* * *$ \\
\hline Within Economics Subject & -0.670 & 0.216 & $* * *$ & -0.771 & 0.349 & $* * *$ \\
\hline Within Mathematics Subject & 0.105 & 0.038 & $* * *$ & 0.297 & 0.084 & $* * *$ \\
\hline Within Science or Humanities Subjects & -0.249 & 0.036 & $* * *$ & -0.242 & 0.015 & $* * *$ \\
\hline Teacher Training Courses & 0.786 & 0.279 & $* * *$ & 0.952 & 0.445 & $* * *$ \\
\hline Teacher: Teacher from School & 0.789 & 0.382 & $* *$ & 0.808 & 0.323 & $* *$ \\
\hline Average Class Size & 0.038 & 0.026 & & 0.863 & 0.515 & \\
\hline Ratio of Schoolgirls at class & 0.573 & 0.874 & & 0.039 & 0.030 & \\
\hline \multicolumn{7}{|l|}{ Interaction: Computer/tablet at school and } \\
\hline Financial Education within Mathematics & -0.434 & 0.132 & $* * *$ & -0.830 & 0.211 & $* * *$ \\
\hline \multicolumn{7}{|l|}{ Interaction: ICT for homework and in Financial } \\
\hline \multicolumn{7}{|l|}{ Education within Mathematics } \\
\hline 1-2 times/week & 0.184 & 0.067 & $* * *$ & 0.180 & 0.063 & $* * *$ \\
\hline Almost every day & -0.263 & 0.025 & $* * *$ & -0.350 & 0.075 & $* * *$ \\
\hline Everyday & -0.337 & 0.067 & $* *$ & -0.413 & 0.065 & $* *$ \\
\hline Constant & 0.468 & 0.421 & & -0.998 & 0.572 & $* *$ \\
\hline$\mu($ mixed effect $)$ & & & & 1.410 & 0.308 & $* * *$ \\
\hline$\sigma($ mixed effect) & & & & 0.257 & 0.081 & $* * *$ \\
\hline$\rho$ & 0.751 & 0.178 & $* * *$ & 0.271 & 0.101 & $* * *$ \\
\hline Log likelihood & & -360.159 & & & -347.454 & \\
\hline $\mathrm{N}$ & & 166 & & & 166 & \\
\hline
\end{tabular}

Same footnote than previous table.

Figure 1 shows the density functions corresponding to the effect of Financial Education on Mathematics in TP and NP Communities. The mean effect of the Financial Education variable on Mathematics is more intense in NP Communities than for TP Communities (1.410 compared to 1.222) and it is also more concentrated. This implies that in TP Communities there are students who receive great benefit from learning Financial Education in regards to Mathematics scores (30\% of the distribution is above $2)$, but there are also students who are found in the opposite situation $(10.62 \%$ are below zero), i.e., that obtain good results in Financial Education, but poor results in Mathematics.

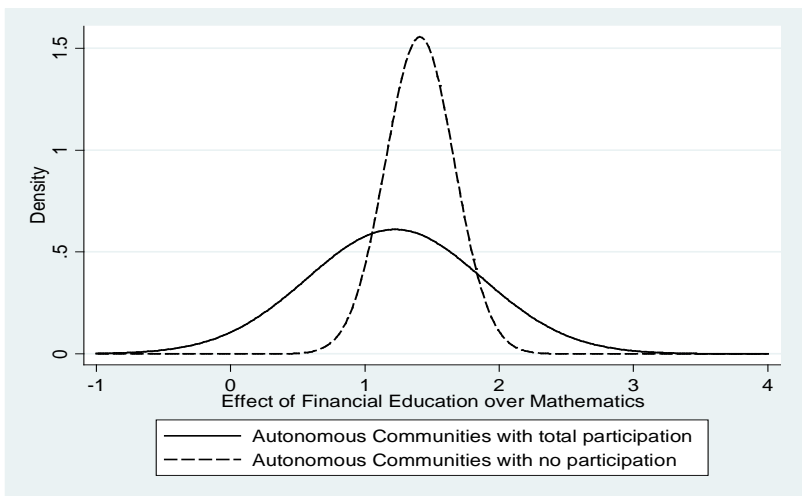

Figure 1. Density Functions of the Effect of Financial Education on Mathematics Scores According to Participation in School Program 2.0 (repeating and non-repeating students are included) 
The sample size of the TP Communities allows calculation of the bivariate probit model with mixed effects distinguishing between repeating and non-repeating students $\mathrm{We}$ consider that this analysis is interesting given the relevant proportion of repeating students (for TP Communities, $25 \%$ of students had repeated one year and nearly $10 \%$ had repeated two years). The results of the estimation are not shown due to their size, but are available on request from the authors. Figure 2 shows the density functions for repeating and non-repeating students in TP Communities.

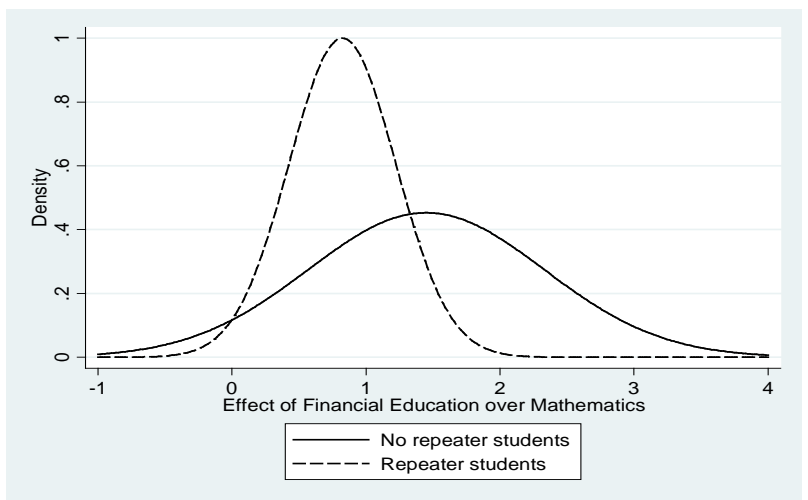

Figure 2. Density Functions of the Effect of Financial Education on Mathematics Scores According to Repeating a School Year. Only Communities with Total Participation in School Program 2.0

The effect of Financial Education on Mathematics is, on average, 1.4491 for nonrepeating students compared to 0.8234 repeating students. Consequently, in TP Communities, there is a multiplicative effect (which also might be described as a positive externality) of Financial Education on Mathematics for non-repeating students. However, for students who have repeated a school year, the transmission of knowledge or skills from Financial Education to Mathematics occurs at a lower rate (the sample size does not allow us to differentiate between students who have repeated on one or two school years).

These results appear to suggest that for some students learning operates like an osmosis system, in a manner that knowledge/skills from Financial Education are transferred to the field of Mathematics with a clearly positive effect. However, there are other students that seem to operate within a separate system, whereby they "do" well in Financial Education but have less satisfactory results in Mathematics.

\section{Conclusions}

This work has confirmed the importance of young people to understand Financial Education concepts, not only because it involves a significant improvement for scores in this area, but also because it holds, to a great extent, a beneficial effect on the skills acquired within the subject of Mathematics. It has shown that a greater benefit is obtained when the contents of Financial Education are taught in conjunction with the contents of the subject of Mathematics. From the point of view of Higher Education, the main recommendation of this paper is that faculties preparing teachers for primary and secondary schools should include the standards of financial literacy and the relationship with mathematical concepts in their academic programmes. 
Regarding the influence of ICT on the skills for both subjects, the benefit of having a computer for personal use by students is observed, both for school and home use. This positive effect is associated with a moderate use of computers (1-2 times/week), but is not observed for the case of daily use. However, we must interpret the results with certain caution, as not much time has passed since the implementation of these new teaching methodologies, so we should expect to see a "learning effect" over time. In this case, future waves of PISA should be should be used to test this hypothesis.

It has been verified that $100 \%$ of students in Communities that have not participated in School Program 2.0 have experienced a positive effect of Financial Education on Mathematics, meanwhile Communities with total participation had approximately $10 \%$ of students with mixed results in both areas. Given that the analysis included variables related to the student, his/her family, the use of ICT as a teaching methodology, and the means of explaining how Financial Education in relation to other subjects, we must consider which other variables (motivational, linguistic, procedural) are hindering student learning, since these deficiencies in their education could imply a major detriment to his/her subsequent development as an adult.

\section{References}

Buscha, F., Conte, A. (2010). The impact of truancy on educational attainment: a bivariate ordered probit estimator with mixed effects. JENA Economic Research Papers N0. 062. Volpe

Cole, S., Sampson, T., Zia, B. (2011). Prices or knowledge? What drives demand for financial services in emerging markets? The Journal of Finance, 66, 1933-1967.

Lester, W.F., Williams, V.J. (2010). Interactive investor education: an exploratory impact study in non-traditional learning environments. Business Education Innovation Journal, 2, 44-52.

Lusardi, A., Mitchell, O.S. (2009). How ordinary consumers make complex economic decisions: financial literacy and retirement readiness. Working Paper 15350. National Bureau of Economic Research.

Lusardi, A., Tuffano, P. (2009). Debt literacy, financial experiences and overindebtedness. NBER Working Paper No. 14808.

OECD, (2014). PISA 2012. Technical Report. Available at: http://www.oecd.org/pisa/pisaproducts/PISA-2012-technical-report-final.pdf

Pinto, M.B, Mansfield, P.M., Parente, D.H. (2005). Information learned from socialization agents: its relationship to credit card use. Family and Consumer Sciences Research Journal, 33, 357-367.

Sajaia, X. (2008). Maximum likelihood estimation of a bivariate ordered probit model: implementation and Monte Carlo simulations. The Stata Journal 3(2), 311-328.

Van Rooij, M.A., Lusardi, A., Alessie, R. (2011). Financial literacy and stock market participation. Journal of Financial Economics, 110, 449-472.

Williams, S. (2010). Parental influence on the financial literacy of their school-aged children: an exploratory study. Exceptional Children, Journal of Special Education, I, 23-33. 